FAYAD, J.A.; FONTES, P.C.R.; CARDOSO, A.A.; FINGER, L.F.; FERREIRA, F.A. Crescimento e produção do tomateiro cultivado sob condições de campo e de ambiente protegido. Horticultura brasileira, Brasília, v. 19, n. 3, p. 232-237, novembro 2.001.

\title{
Crescimento e produção do tomateiro cultivado sob condições de campo e de ambiente protegido.
}

\author{
Jamil Abdalla Fayad ${ }^{1}$; Paulo Cezar Rezende Fontes²; Antônio Américo Cardoso²; Fernando Luiz Finger²; \\ Francisco Affonso Ferreira ${ }^{2}$ \\ ${ }^{1}$ EPAGRI- Estação experimental de Caçador, C. Postal 591, CEP 89.500-000, Caçador-SC; ${ }^{2}$ UFV-Departamento de Fitotecnia, $36.571-$ \\ 000, Viçosa- MG; E.mail: pacerefo@mail.ufv.br
}

\section{RESUMO}

Foram realizados dois experimentos, na Universidade Federal de Viçosa, objetivando caracterizar o crescimento e a produção de frutos pelo tomateiro cultivado sob condições de campo e de ambiente protegido. O primeiro, com a cultivar Santa Clara, cultivada a campo no sistema de cerca cruzada e sete cachos. O segundo, em estufa plástica, com o híbrido EF-50, conduzidas verticalmente e mantendo-se oito cachos. Ambos os experimentos foram delineados em blocos ao acaso, com quatro repetições. O primeiro constituído por oito e o segundo, por nove tratamentos. Em ambos os experimentos, os frutos acumularam mais matéria seca que os demais órgãos da planta. No primeiro experimento, os valores máximos de matéria seca total e de frutos, altura de planta, taxa de crescimento absoluto $(\mathbf{G})$, taxa crescimento relativo $(\mathbf{R})$, taxa assimilatória líquida (E) e índice de área foliar (L) foram 406,0 g planta $^{-1} ; 207,0 \mathrm{~g}$ planta ${ }^{-1} ; 146,0 \mathrm{~cm} ; 8.552,0 \mathrm{mg}_{\text {planta }}{ }^{-1} \mathrm{dia}^{-1} ; 87,0 \mathrm{mg} \mathrm{g}^{-1} \mathrm{dia}^{-1} ; 38,0$ $\mathrm{mg} \mathrm{dm}{ }^{-2} \mathrm{dia}^{-1}$ e 4,1 , respectivamente. Em ambiente protegido, os valores máximos daquelas características enumeradas anteriormente foram 398,0 g planta $^{-1} ; 269,0$ g planta $^{-1} ; 85,0 \mathrm{~cm} ; 5.710,0 \mathrm{mg}$ planta ${ }^{1} \mathrm{dia}^{-1} ; 54,0 \mathrm{mg} \mathrm{g}^{-1} \mathrm{dia}^{-1} ; 464,0 \mathrm{mg} \mathrm{dm}^{-2} \mathrm{dia}^{-1} \mathrm{e} 4,5$, respectivamente. A produção total de frutos, no primeiro experimento, foi $94,8 \mathrm{t} \mathrm{ha}^{-1}$; destes, $93 \%$ foram classificados como comerciais, equivalente a $738,0 \mathrm{~kg} \mathrm{ha}^{-1} \mathrm{dia}^{-1}$. No segundo experimento, a produção total de frutos foi $115,4 \mathrm{t} \mathrm{ha}^{-1}$; destes, $94 \%$ foram classificados como comerciais, equivalente a $807,0 \mathrm{~kg} \mathrm{ha}^{-1} \mathrm{dia}^{-1}$.

Palavras-chave: Lycopersicon esculentum Mill, plasticultura, análise do crescimento, rendimento, qualidade.

\begin{abstract}
Tomato plant growth and fruit yield under field and protected conditions.

Two experiments were conducted at Universidade Federal de Viçosa (Brazil) to evaluate tomato plant growth and fruit yield under field and protected conditions. In the first experiment, tomato cv. Santa Clara was grown in the field and supported with stakes and each with seven clusters. In the second one tomato hybrid EF-50 was grown in plastic greenhouse and plants were vertically trellised and pruned at eight clusters stage. Both experiments were designed as randomized complete blocks, with four replicates. In the first and second experiment eight and nine treatments were evaluated, respectively. In both experiments, the fruits accumulated more dry matter than the other organs of the plant. In the first experiment, the highest values of plant and fruit dry matters, plant height, absolute growth rate $(\mathbf{G})$, relative growth rate $(\mathbf{R})$, net assimilation rate $(\mathbf{E})$, and leaf area index $(\mathbf{L})$ were $406.0 \mathrm{~g} \mathrm{plant}^{-1} ; 207.0 \mathrm{~g} \mathrm{plant}^{-1} ; 146.0$ $\mathrm{cm} ; 8,552.0 \mathrm{mg}$ plant $^{-1}$ day $^{-1} ; 87.0 \mathrm{mg} \mathrm{g}^{-1}$ day $^{-1} ; 38.0 \mathrm{mg} \mathrm{dm}^{-2}$ day $^{-1}$ and 4.1 , respectively. In the second experiment, the highest values for the above characteristics were $398.0 \mathrm{~g} \mathrm{plant}^{-1} ; 269.0 \mathrm{~g} \mathrm{plant}^{-1}$; $85.0 \mathrm{~cm} ; 5,710.0 \mathrm{mg} \mathrm{plant}^{-1} \mathrm{day}^{-1} ; 54.0 \mathrm{mg} \mathrm{g}^{-1}$ day $^{-1} ; 464.0 \mathrm{mg} \mathrm{dm}^{-2}$ day $^{-1}$ and 4.9 , respectively. In the first experiment, total fruit yield reached $96.8 \mathrm{t} \mathrm{ha}^{-1} ; 93 \%$ of them were classified as marketable, corresponding to $738.0 \mathrm{~kg} \mathrm{ha}^{-1} \mathrm{day}^{-1}$ yield. In the second experiment, total yield was $115.4 \mathrm{t} \mathrm{ha}^{-1}$ with $94 \%$ of them graded as marketable, corresponding to $807.0 \mathrm{~kg} \mathrm{ha}^{-1} \mathrm{day}^{-1}$ yield.
\end{abstract}

Keywords: Lycopersicon esculentum Mill, plasticulture, growth analysis, yield, quality.

(Aceito para publicação em 30 de julho de 2.001)

$\mathrm{O}$ conhecimento sobre o crescimento das espécies cultivadas permite planejar métodos racionais de cultivo, contribuindo na expressão do potencial de espécies vegetais, além de fornecer dados para a construção de modelos matemáticos descritores do crescimento. Os princípios e práticas de análise de crescimento têm como objetivo descrever e interpretar a performance das espécies produzidas em ambiente natural ou controlado (Hunt, 1990). Fundamenta-se na medida sequencial do acúmulo de matéria orgânica pela planta, determinada normalmente pela mensuração da massa da planta e, ou de suas partes secas (frutos, caule, folhas e outros). Portanto, a análise de crescimento expressa as condições morfofisiológicas da planta e avalia sua produção líquida, derivada do processo fotossintético, sendo o resultado do desempenho do sistema assimilatório durante certo período de tempo. Além da massa da matéria seca, via de regra, a área foliar é também determinada (Benincasa, 1988).

Ao analisar o crescimento do tomateiro, Heuvelink (1995) verificou que do total da matéria seca produzida pela cv. Counter, cultivada em ambiente protegido, no período de verão, $60 \%$ da matéria seca foram alocados nos frutos,
$28 \%$ nas folhas e $12 \%$ nas hastes. Os valores de área foliar específica (SLA), taxa de crescimento absoluto $(\mathbf{G})$ e índice de área foliar $(\mathbf{L})$ determinados, foram de $250 \mathrm{~cm}^{2} \mathrm{~g}^{-1} ; 20 \mathrm{~g} \mathrm{~m}^{-2} \mathrm{e} 3$, respectivamente. Tanaka et al. (1974) também encontraram $\mathbf{L}$ de 3, aos 120 dias após o transplantio para tomate cultivar Ogata Fukuju, cultivado sob condições de campo, e podado acima do terceiro cacho, sendo a relação número de frutos/número de folhas de 1,39. Em experimento conduzido sob condições de campo, com plantas da cultivar Santa Cruz Kada, podadas acima do terceiro cacho, determinaram-se como valores 
máximos para a relação número de frutos/número de folhas de 1,64; $\mathbf{L}$ de 2,2 e taxa assimilatória líquida (E) de $23 \mathrm{mg}$ $\mathrm{dm}^{-2} \mathrm{dia}^{-1}$, aos 56 e 70 dias após transplantio, respectivamente e área foliar por fruto de $450 \mathrm{~cm}^{2}$ aos 56 dias após o transplantio (Peluzio, 1991). Em outros países, diversas dessas características são combinadas em modelos matemáticos que buscam descrever o crescimento do tomateiro. Estes modelos têm tido importância crescente nos trabalhos de pesquisa, principalmente em condições controladas (Bertin \& Heuvelink, 1993).

No Brasil, são raros os trabalhos sobre a dinâmica da produção e alocação de biomassa em partes do tomateiro. Além do total de biomassa alocada nos frutos, é necessário o conhecimento de seu tamanho e qualidade, em função do ambiente de cultivo e aspectos fundamentais para a comercialização. $\mathrm{O}$ objetivo deste trabalho foi caracterizar o crescimento e a produção de frutos do tomateiro, das cultivares Santa Clara, cultivada sob condições de campo, e EF50, em ambiente protegido.

\section{MATERIAL E MÉTODOS}

Foram instalados dois experimentos na Universidade Federal de Viçosa. As mudas, para ambos os experimentos, foram produzidas em copinhos de jornal de $9 \mathrm{~cm}$ de altura e $5,5 \mathrm{~cm}$ de diâmetro, preenchidos com o substrato formado por $600 \mathrm{~kg}$ de terra, $150 \mathrm{~kg}$ de esterco de galinha e $23 \mathrm{~kg}$ da fórmula 05-20-10. Foram realizadas as semeaduras, com três sementes por copinho, à profundidade de $0,5 \mathrm{~cm}$. Quando as mudas apresentaram a primeira folha verdadeira, foi realizado o desbaste, deixando uma muda por copinho. O primeiro experimento foi realizado sob condições de campo, no período de 20 de março a 18 de julho de 1997, utilizando-se a cultivar Santa Clara, conduzida no espaçamento de $1,0 \mathrm{~m}$ entre linhas e $0,5 \mathrm{~m}$ entre plantas, com uma muda por cova, duas hastes e tutoradas com bambu, no sistema de cerca cruzada, e podadas após a terceira folha acima do quarto cacho floral, na haste principal, e do terceiro cacho floral, na haste secundária. O método de irrigação foi por sulco. No sulco de plantio, efetuou-se uma adubação com $10 \mathrm{t}$ $\mathrm{ha}^{-1}$ de esterco de galinha, $10 \mathrm{~kg} \mathrm{ha}^{-1} \mathrm{de}$ bórax, $200 \mathrm{~kg} \mathrm{ha}^{-1}$ de sulfato de magnésio, $80 \mathrm{~kg} \mathrm{ha}^{-1}$ de $\mathrm{N}, 180 \mathrm{~kg} \mathrm{ha}^{-1}$ de $\mathrm{P}_{2} \mathrm{O}_{5}$ e $50 \mathrm{~kg} \mathrm{ha}^{-1}$ de $\mathrm{K}_{2} \mathrm{O}$ (Comissão..., 1989), respectivamente, na forma de uréia, superfosfato simples e cloreto de potássio. As adubações de cobertura foram realizadas $15 ; 30$ e 50 dias após o transplantio das mudas, manualmente, ao longo das linhas de plantio. Na primeira adubação de cobertura, utilizou-se $80 \mathrm{~kg} \mathrm{ha}^{-1}$ de N; $180 \mathrm{~kg}$ $\mathrm{ha}^{-1}$ de $\mathrm{P}_{2} \mathrm{O}_{5}$ e $50 \mathrm{~kg} \mathrm{ha}^{-1}$ de $\mathrm{K}_{2} \mathrm{O}$ e na segunda e terceira, $80 \mathrm{~kg} \mathrm{ha}^{-1}$ de $\mathrm{N}$ e 50 $\mathrm{kg} \mathrm{ha}^{-1}$ de $\mathrm{K}_{2} \mathrm{O}$.

$\mathrm{O}$ segundo experimento foi desenvolvido em estufa plástica modelo arco, com 9,0 m de largura, 40,0 m de comprimento e 3,2 $\mathrm{m}$ de altura, com laterais abertas e coberta com filme de polietileno $0,1 \mathrm{~mm}$ de espessura. Nesse experimento foi cultivado o híbrido EF50, em fileiras duplas distanciadas em $1,0 \mathrm{~m}$, com $0,5 \mathrm{~m}$ entre fileiras simples. O espaçamento entre plantas foi de 0,6 $\mathrm{m}$, com uma muda por cova. As plantas foram tutoradas na vertical e mantidos oito cachos florais por planta. A irrigação foi por gotejamento. A necessidade de água foi calculada pelo método do tanque classe A, considerando-se o coeficiente do tanque de 0,75 e coeficientes de cultura variáveis, dependendo do estádio de desenvolvimento da planta (Carrijo et al., 1996). Na adubação no sulco de plantio, foram aplicados 360 $\mathrm{kg} \mathrm{ha}^{-1}$ de $\mathrm{P}_{2} \mathrm{O}_{5}$, na forma de superfosfato simples, e $200 \mathrm{~kg} \mathrm{ha}^{-1}$ de sulfato de magnésio. As adubações de cobertura foram efetuadas junto com a água de irrigação em 24 aplicações, utilizandose $255 \mathrm{~kg} \mathrm{ha}^{-1}$ de $\mathrm{N}$, na forma de uréia, $240 \mathrm{~kg} \mathrm{ha}^{-1}$ de $\mathrm{K}_{2} \mathrm{O}$, na forma de cloreto de potássio, $10 \mathrm{~kg} \mathrm{ha}^{-1}$ de bórax, $10 \mathrm{~kg}$ $\mathrm{ha}^{-1}$ de sulfato de zinco e $200 \mathrm{~g} \mathrm{ha}^{-1} \mathrm{de}$ molibdato de sódio. A concentração de nutrientes na água de irrigação sempre foi menor que $700 \mathrm{mg} \mathrm{L}^{-1}$, para garantir uniformidade de distribuição dos nutrientes. Os fertilizantes bórax, sulfato de zinco e molibdato de sódio foram aplicadas na água de irrigação, parcelados em cinco aplicações.

Ambos os experimentos foram delineados em blocos casualizados com quatro repetições. O primeiro com oito e o segundo com nove tratamentos. Cada tratamento correspondeu a uma época de amostragem, realizada em intervalos de quinze dias a partir do transplantio. Foram colhidas, aleatoriamente, duas plantas por amostragem. No primeiro experimento, o bloco foi constituído por seis fileiras de plantas com 14,5 m de comprimento e no segundo, por cinco fileiras de plantas com 17,4 m de comprimento. Em ambos os experimentos, a terceira e a quarta fileiras do bloco continham as planta úteis, sendo as demais fileiras mais as duas plantas das extremidades da terceira e quarta fileiras do bloco consideradas bordaduras.

Em cada experimento, as duas plantas amostradas em cada época (tratamento) e em cada repetição foram cortadas ao nível do solo e divididas em caule, folha, cacho e fruto. Em seguida, utilizando-se os valores médios das duas plantas, foram determinadas características de crescimento e produção de frutos.

O crescimento foi caracterizado pelos parâmetros: produção de matéria seca das folhas, caule, cacho e frutos, área foliar, altura da planta, número de frutos, número de folhas, números de cachos, taxa de crescimento absoluto da cultura (G), taxa de crescimento relativo $(\mathbf{R})$, taxa assimilatória líquida $(\mathbf{E})$, índice de área foliar $(\mathbf{L})$ e área foliar específica (SLA).

Para as determinações da produção de matéria seca dos diversos órgãos, esses foram separados e acondicionados em sacos de papel e secados em estufa com circulação forçada de ar a $70^{\circ} \mathrm{C}$. Durante o ciclo cultural, as folhas secas das plantas úteis foram coletadas, acondicionadas em sacos de papel, secadas em estufa, pesadas e seus valores acrescentados aos respectivos tratamentos (época de amostragem).

A área foliar foi determinada com medidor integrador eletrônico. Semelhante ao procedimento adotado para as folhas secas, para todos os frutos maduros das plantas úteis foram coletados, contados e pesados antes e após a secagem, registrando-se a data de coleta. Seus valores foram creditados à respectiva época de amostragem.

A taxa de crescimento absoluto (G) foi obtida por meio da derivada primei- 


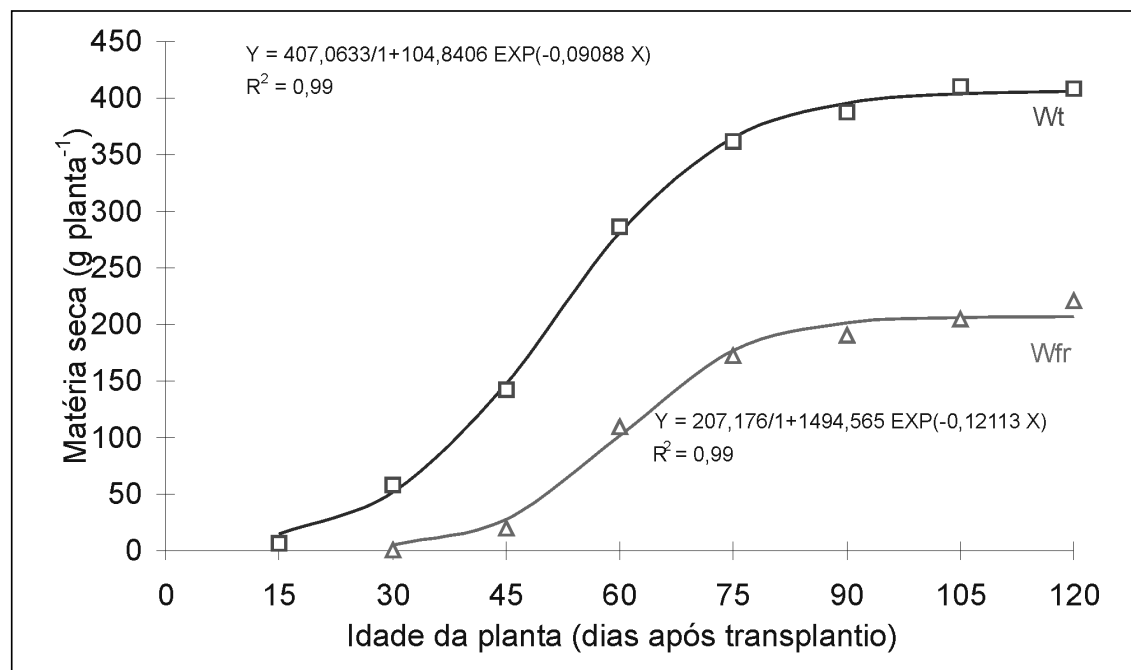

Figura 1. Produção de matéria seca total (Wt) e dos frutos (Wfr), em função da idade do tomateiro cultivado no campo, cv. Santa Clara, em função da idade. Viçosa, UFV, 1997.
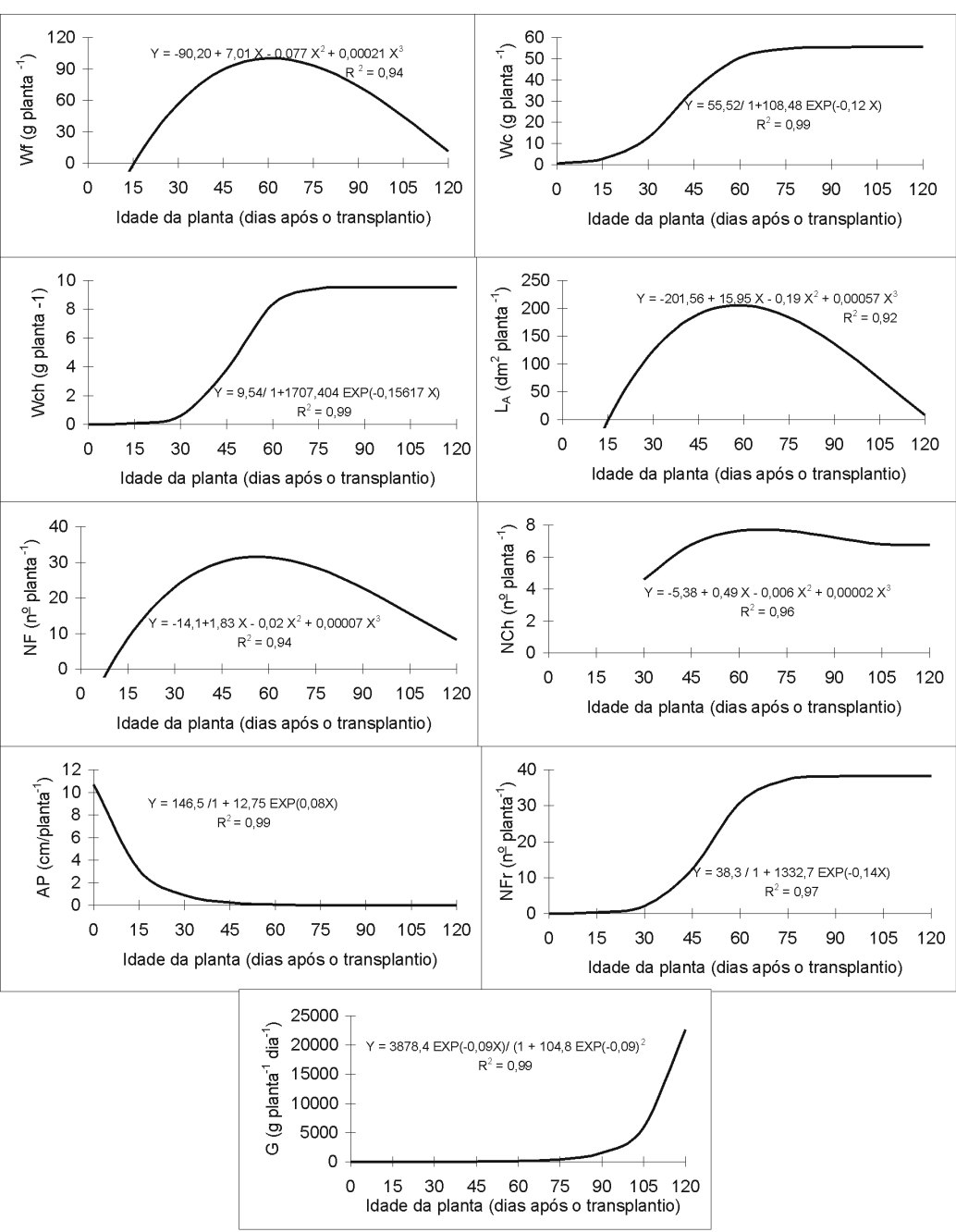

Figura 2. Produção de matérias secas de folhas vivas (Wf), de caule (Wc) e de cachos (Wch), área foliar $\left(\mathrm{L}_{\mathrm{A}}\right)$, números de folhas $(\mathrm{NF})$ e de cachos $(\mathrm{NCh})$, altura de planta $(\mathrm{AP})$, número de frutos $(\mathrm{Nfr})$ e taxa de crescimento absoluto $(\mathbf{G})$ em função da idade do tomateiro cultivado no campo, cv. Santa Clara, expressa em dias após transplantio. Viçosa, UFV, 1997. ra da equação ajustada ao peso da matéria seca da planta $(\mathrm{Wt})$. A taxa de crescimento relativo $(\mathbf{R})$ foi obtida dividindo-se o valor da taxa de crescimento absoluto $(\mathbf{G})$ pelo peso da matéria seca da planta para cada época. De forma semelhante, obteve-se a taxa assimilatória líquida (E), por meio da divisão do valor da taxa de crescimento absoluto $(\mathbf{G})$ pelo valor da área foliar $\left(\mathrm{L}_{\mathrm{A}}\right)$. $\mathrm{O}$ índice de área foliar $(\mathbf{L})$ foi obtido pela divisão do valor da área foliar $\left(\mathrm{L}_{\mathrm{A}}\right)$ pela área ocupada pela planta $(\mathrm{S})$. Para a determinação do valor da área foliar específica (SLA), dividiu-se o valor da área foliar $\left(\mathrm{L}_{\mathrm{A}}\right)$ pelo peso da matéria seca foliar (Wf).

$\mathrm{Na}$ determinação da produção classificada dos frutos foram realizadas colheitas de frutos fisiologicamente maduros aos $81 ; 89 ; 95 ; 102 ; 110 ; 116 \mathrm{e}$ 120 dias e aos $98 ; 102 ; 109 ; 119 ; 126$ e 135 dias após o transplantio das mudas, para os experimento 1 e 2 , respectivamente. Os frutos colhidos da cultivares Santa Clara e EF-50 foram classificados de acordo com o maior diâmetro transversal, seguindo adaptação da Portaria 553 de 30/08/95 publicado no Diário Oficial da União de 19/09/95.

Todas as características determinadas foram submetidas às análises de variância e de regressão polinomial, utilizado-se o SAEG (Sistema para Análises Estatísticas e Genéticas - UFV).

\section{RESULTADOS E DISCUSSÃO}

\section{Crescimento do tomateiro cultiva-}

\section{do no campo}

A produção de matéria seca $(\mathrm{Wt}) \mathrm{da}$ parte aérea do tomateiro foi maior aos 120 dias após o transplantio das mudas, alcançando 406,3 g planta $^{-1}$ (Figura 1). Os frutos foram o dreno principal da planta desde o início da frutificação até a última colheita de frutos maduros, chegando a acumular $51 \%$ do total da matéria seca produzida pela planta, seguida por $33 \%$ nas folhas, $14 \%$ no caule e por último $2 \%$ nos cachos florais (Figura 2). O caule comportou-se como dreno de assimilados ao longo do ciclo cultural, diferindo dos resultados encontrados por Peluzio (1991), onde atuou como fonte destes ao final do ciclo.

A área foliar e o número de folhas por planta aumentaram até os valores 
máximos de $206 \mathrm{dm}^{2} \mathrm{e} 31$ folhas, aos 58 e 56 dias após o transplantio (Figura 2). Após essas épocas, as diminuições da área foliar e do número de folhas foram ocasionadas pela poda apical e pela senescência e abcisão foliar.

A altura e o número de frutos por planta aumentaram até o final do experimento, atingido os valores de $146 \mathrm{~cm}$ e 38 frutos (Figura 2). Por sua vez, Dechen et al. (1980) obtiveram com tomateiro cv. Kadá conduzido sem poda apical, plantas com $246 \mathrm{~cm}$ de altura.

A eficiência da planta na produção diária de matéria seca pela planta $(\mathbf{G})$ e pelas folhas (E) foram crescentes até os 45 dias, para depois diminuir, assemelhando-se aos valores obtidos por Peluzio (1991). Porém, ganho de matéria seca por unidade de matéria seca já contida na planta $(\mathbf{R})$ diminuiu ao longo do ciclo cultural.

$\mathrm{O}$ índice de área foliar (L) atingiu valor máximo, de 4,12, aos 58 dias, chegando ao final do ciclo com 0,17 , indicando período de senescência e abcisão foliar. A área foliar específica (SLA) diminuiu ao longo do ciclo cultural atingindo o valor mínimo de $0,783 \mathrm{dm}^{2} \mathrm{~g}^{-1}$ 120 dias após o transplantio, indicando aumento da biomassa nas folhas e redução na expansão da área foliar.

O tomateiro cv. Santa Clara, cultivado sob condições de campo, chegou à última colheita de frutos, 120 dias após o transplantio, com reduzida área foliar. Contribuiu para esse comportamento, a ocorrência de algumas doenças como Phytophthora infestans e Alternaria solani.

Crescimento do tomateiro cultivado em ambiente protegido

Houve contínuo acúmulo de matéria seca (Wt) na parte aérea da planta, ao longo do ciclo cultural, atingindo 397,9 g planta $^{-1}$ (Figura 3), distribuídas em $25 \%$ deste total nas folhas (Wf), $5 \%$ no caule (Wc), $2 \%$ nos cachos (Wch) e $68 \%$ nos frutos (Wfr) (Figura 4). Do início da frutificação ao final do ciclo cultural, os frutos representaram os drenos principais da planta. O caule e os cachos comportaram-se como drenos, diferindo dos resultados obtidos por Gargantini \& Blanco (1963) que observaram translocação de assimilados do

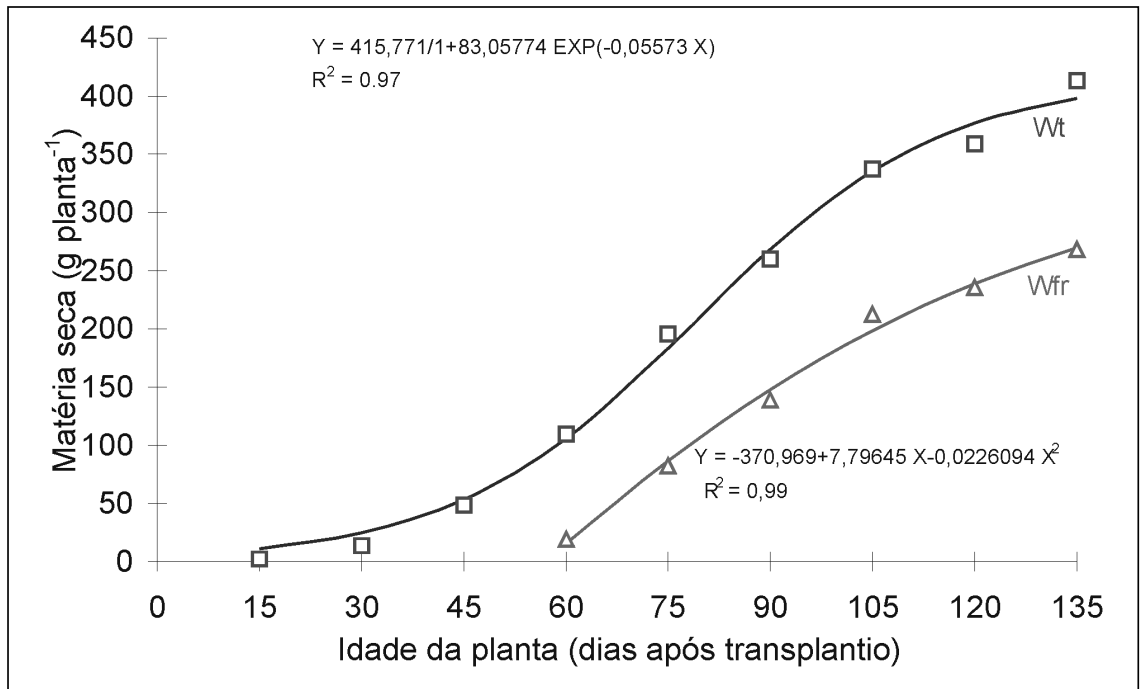

Figura 3. Produções de matéria seca total (Wt) e dos frutos (Wfr), em função da idade do tomateiro cultivado em ambiente protegido, híbrido EF-50, em função da idade. Viçosa, UFV, 1997.

caule para os frutos, ao final do ciclo da planta. Possivelmente, a ausência de translocação de assimilados do caule para outros órgãos da planta seja devida à diminuição da drenagem pela colheita de frutos e à manutenção de alto índice de área foliar até o final do ciclo, suprindo as necessidades de fotoassimilados dos drenos remanescentes.

A área foliar e o número de folhas por planta aumentaram até atingirem valores de $202 \mathrm{dm}^{2}$ e 21 folhas, aos $93 \mathrm{e}$ 81 dias após o transplantio (Figura 4). A estabilização e posterior queda dos valores da área foliar e número de folhas foram causadas pela senescência, abcisão foliar e desbrota. O comportamento observado para a variável área foliar foi semelhante ao relatado por Heuvelink (1995) para a cv. Counter.

A altura e o número de frutos por planta aumentaram até atingirem valores máximos de $84,7 \mathrm{~cm}^{2} 29$ frutos planta ${ }^{-1}, 135$ dias após o transplantio (Figura 4).

A taxa de crescimento absoluto $(\mathbf{G})$ aumentou até atingir o valor de 5.710 mg planta ${ }^{-1}$ dia $^{-1}, 75$ dias após o transplantio. Heuvelink (1995) obteve taxas de crescimento da cultura do tomateiro, em casa de vegetação, variando de quase zero no inverno a $9.500 \mathrm{mg}$ planta $^{-1}$ dia $^{-1}$ no verão. Pardossi et al. (1987) encontraram para o tomateiro, cultivado em solução nutritiva, taxas de crescimento absoluto de 1.640; 3.408; 3.392 e 3.137 mg planta $^{-1}$ dia $^{-1}$, nos pe- ríodos de 21-45; 46-70; 71-95 e 96-120 dias, respectivamente.

As taxas de crescimento relativo (R) e assimilatória líquida (E) diminuíram ao longo do ciclo cultural. Decréscimos nos valores de $\mathbf{R}$, ao longo do ciclo, são comuns para a maioria das espécies, inclusive no tomateiro, estando relacionados aos decréscimos na taxa assimilatória líquida e na razão de área foliar. No entanto, a intensidade desse efeito sobre $\mathbf{R}$ varia entre genótipos de tomateiro (Nieuwhof et al., 1991).

O crescimento do sistema assimilatório da planta, representado pelo índice de área foliar (L), aumentou até os 93 dias, para posteriormente declinar, o que se assemelha aos resultados encontrados por Heuvelink (1995). Possivelmente, a manutenção de alto índice de área foliar até o final do ciclo seja devido às condições climáticas favoráveis no interior da estufa plástica, resultando, principalmente em baixa incidência de doenças e disponibilidade contínua de nutrientes, fornecidos via fertirrigação por gotejamento.

A área foliar específica (SLA) aumentou até os 30 dias após o transplantio, em seguida decresceu até o final do experimento. Heuvelink (1995) encontrou comportamento semelhante ao trabalhar com a cv. Counter, em estufa. A diminuição da SLA indica que houve aumento do conteúdo de matéria seca foliar superior ao da área foliar. 


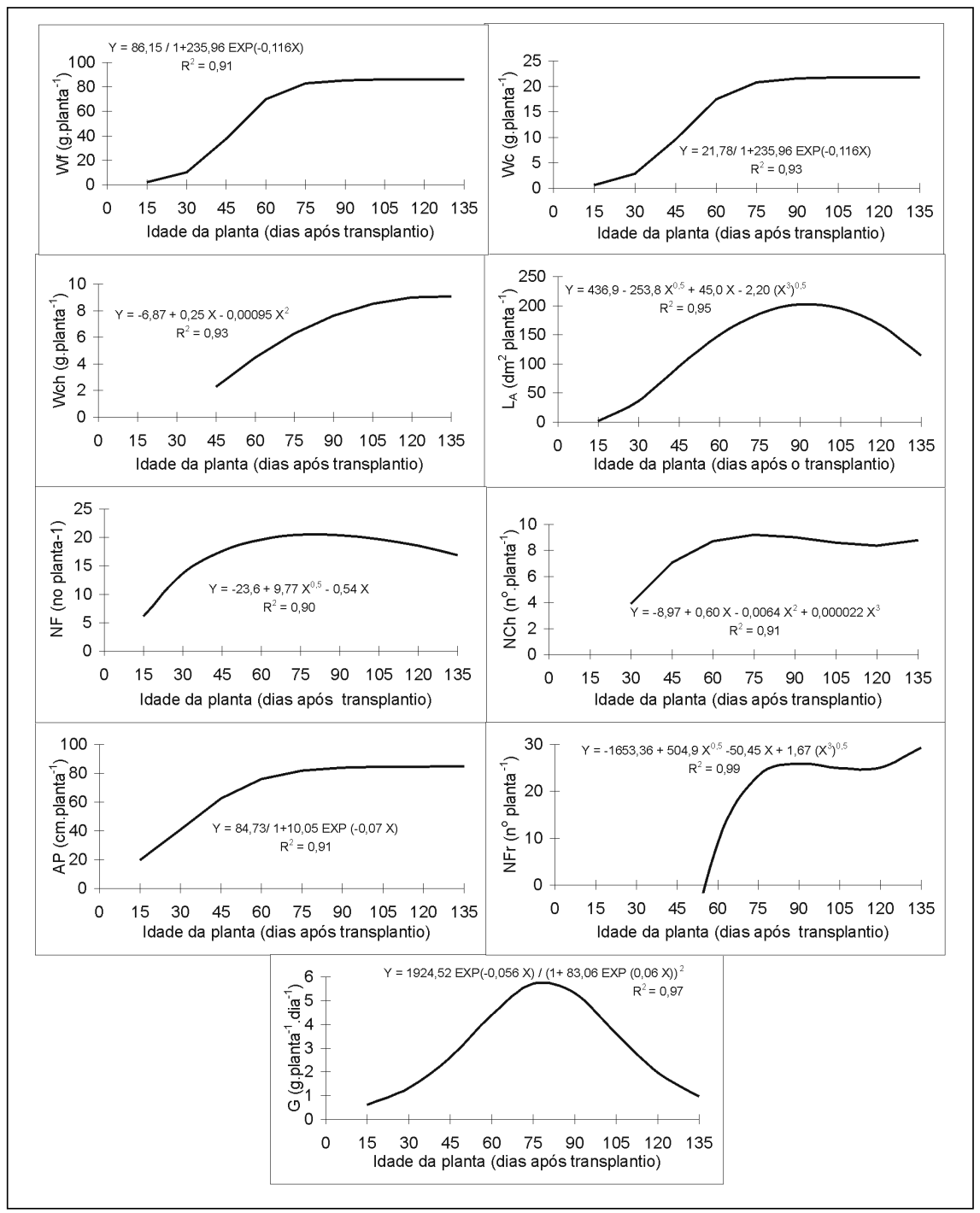

Figura 4. Produção de matérias secas de folhas (Wf), de caule (Wc) e de cachos (Wch), área foliar $\left(\mathrm{L}_{\mathrm{A}}\right)$, número de folhas $(\mathrm{NF})$ e de cachos $(\mathrm{NCh})$, altura de planta $(\mathrm{AP})$, número de frutos (Nfr) e taxa de crescimento absoluto $(\mathbf{G})$ em função da idade do tomateiro cultivado em ambiente protegido, híbrido EF-50, expressa em dias após transplantio. Viçosa, UFV, 1997.

Produção classificada de frutos do tomateiro cultivado no campo

As produções total e comercial de frutos maduros atingiram, aos 120 dias após o transplantio $4.741,18$ e 4.430,50 g planta ${ }^{-1}$, equivalendo a produtividades de 94.823 e $88.610 \mathrm{~kg} \mathrm{ha}^{-1}$ ou 790 e 738 $\mathrm{kg} \mathrm{ha}^{-1}$ dia $^{-1}$, distribuídas em sete colheitas de frutos maduros realizadas aos 81 ; 89; 95; 102; 110; 116 e 120 dias pós o transplantio. A produtividade obtida foi superior aos $635 \mathrm{~kg} \mathrm{ha}^{-1} \mathrm{dia}^{-1}$, obtidos por Sampaio (1996), com a cv. Santa Clara, cultivada durante os meses de julho a novembro, em Viçosa. Silva \& Vizzotto (1990), trabalhando com tomate cv. Angela Gigante, na região de Blumenau (SC), obtiveram $53.000 \mathrm{~kg}$
71 e 52 g, respectivamente. Frutos das duas primeiras classes são os mais procurados nos mercados mais exigentes, propiciando vendas rápidas e de melhor preço, garantindo maiores lucros ao tomaticultor.

Produção classificada de frutos do tomateiro cultivado em ambiente protegido

Apesar de terem sido feitas seis colheitas de frutos maduros, aos 98; 102; 109; 119; 126 e 135 dias a produção de frutos concentrou-se no período de 109 a 135 dias após o transplantio, tendo sido obtida uma produção total de $5.245 \mathrm{~g}$ planta $^{-1}$, equivalendo a $115.390 \mathrm{~kg} \mathrm{ha}^{-1}$ ou $854 \mathrm{~kg} \mathrm{ha}^{-1} \mathrm{dia}^{-1}$. A produção comercial (frutos gigantes, grandes, médios e pequenos) atingiu $94,45 \%$ da produção total, equivalendo à produtividade de $807 \mathrm{~kg} \mathrm{ha}^{-1} \mathrm{dia}^{-1}$, enquanto as três maiores classes representaram $90,93 \%$ da produção. Os pesos médios dos frutos gigante, grande, médio e pequeno foram de $415 ; 267 ; 168$ e $84 \mathrm{~g}$, respectivamente. Esses dados estão entre as produtividades obtidas por Streck et al. (1996) de $241 \mathrm{~kg} \mathrm{ha}^{-1} \mathrm{dia}^{-1}\left(40 \mathrm{t} \mathrm{ha}^{-1}\right)$ a $954 \mathrm{~kg}$ $\mathrm{ha}^{-1} \mathrm{dia}^{-1}\left(143 \mathrm{t} \mathrm{ha}^{-1}\right)$ com diversas cultivares conduzidas em estufa, no RS, nos períodos de outono-inverno e invernoprimavera, em ciclos de 166 e 150 dias após o transplantio. Também Fontes $e t$ al. (1997), que conduziram experimento em estufa plástica, em Viçosa, com o híbrido EF-50, obtiveram $190.000 \mathrm{~kg} \mathrm{ha}^{-1}$, correspondente a $1.180 \mathrm{~kg} \mathrm{ha}^{-1} \mathrm{dia}^{-1}$.

\section{LITERATURA CITADA}

ha- ${ }^{-1}$, correspondendo a $393 \mathrm{~kg} \mathrm{ha}^{-1} \mathrm{dia}^{-1}$, aproximando-se da média de produtividade obtidas pelos tomaticultores brasileiros. Fontes et al. (1987) obtiveram a produtividade de $83.500 \mathrm{~kg} \mathrm{ha}^{-1}$, correspondente a $628 \mathrm{~kg} \mathrm{ha}^{-1} \mathrm{dia}^{-1}$ de frutos comerciais, nos meses de agosto a dezembro, com a cv. Príncipe Gigante, em Ponte Nova (MG). A soma das produções de frutos classificados como graúdo AA e graúdo A foi de $3.649,3 \mathrm{~g}$ planta ${ }^{-1}$, equivalendo a $608 \mathrm{~kg} \mathrm{ha}^{-1} \mathrm{dia}^{-1}$, cerca de $77 \%$ da produção total. As produções concentraram-se nas terceira, quarta e quinta colheitas.

Os pesos médios dos frutos graúdos AA, graúdo A, médio extra, médio especial e pequeno foram $185 ; 135 ; 92$;
BENINCASA, M.M.P. Análise de crescimento de plantas. Jaboticabal, SP: FCAV-UNESP, 1988. 41 p. BERTIN, N.; HEUVELINK, E. Dry matter production in a tomato crop: comparison of two simulation models. Journal of Horticultural Science, v. 68, p. 995-1011, 1993.

CARRIJO, O.A.; MAKISHIMA, N.; OLIVEIRA, C.A.S.; REIS, N.V.B.; FONTES, R.R. Fatores de evaporação do tanque classe $\mathrm{A}$ e níveis de fertirrigação com nitrogênio e potássio afetando o cultivo protegido de tomate. Horticultura Brasileira, Brasília, v. 14, n. 1, p. 78, 1996.

COMISSÃO DE FERTILIDADE DO SOLO DE MINAS GERAIS. Recomendações para uso de corretivos e fertilizantes em Minas Gerais; $4^{\text {a }}$ aproximação. Lavras, 1989.76 p.

DECHEN, A.R.; HAAG, H.P.; SARRUG, J.R.; OLIVEIRA, G.D. Nutrição mineral de hortaliças, Efeitos de doses de cálcio na solução nutritiva, no desenvolvimento e nos teores de $\mathrm{N}, \mathrm{P}, \mathrm{K}, \mathrm{Ca}, \mathrm{Mg}$ e $\mathrm{S}$ em plantas de tomateiro. Anais ESALQ, Piracicaba, v. 37, p. 1009-1057, 1980. 
FONTES, P.C.; NAZAR, R.A.; CAMPOS, J.P. Produção e rentabilidade da cultura do tomateiro afetadas pela fertilização e pelo sistema de condução. Revista Ceres, Viçosa, v. 34, n. 194, p. 355365, 1987.

FONTES, P.C.R.; DIAS, E.N.; ZANIN, S.R.; FINGER, F.L. Produção de cultivares de tomate em estufa coberta com plástico. Revista Ceres, Viçosa, v. 44, n. 252, p. 152-160, 1997.

GARGANTINI, H.; BLANCO, H.G. Marcha de absorção de nutrientes pelo tomateiro. Bragantia, Campinas, v. 56, p. 693-713, 1963.

HEUVELINK, E. Growth, development and yield of a tomato crop: periodic destrutive measurements in greenhouse. Scientia Horticulturae, v. 61, p. 77-99, 1995.

HUNT, R. Basic growth analysis. London: Unwin Hyman, 1990. 112 p.
NIEUWHOF, M.; GARRETSEN, F.; VAN OEVEREN, J.C. Growth analyses of tomato genotypes grown under low energy condictions. Netherlands Journal of Agricultural Science, v. 39, p. 191-196. 1991.

PARDOSSI, A.; TOGNONI, F.; BERTERO, G. The influence of nutrient solution concentration on growth, mineral uptake, and yield of tomato plants grown in N.F.T. Advances Horticultural Science, v. 10, p. 55-60, 1987.

PELUZIO, J.M. Crescimento e partição de assimilados em tomateiro (Lycopersicon esculentum, Mill) após a poda apical. Viçosa, MG: UFV, 1991, 49 p. (Tese mestrado), Universidade Federal de Viçosa, 1991.
SAMPAIO, R.A. Produção, qualidade dos frutos e teores de nutrientes no solo e no peciolo do tomateiro, em função da fertigação potássica e da cobertura plástica do solo. Viçosa, MG: UFV, 1996, 117 p. (Tese doutorado), Universidade Federal de Viçosa. 1996.

SILVA, A.A.; VIZZOTTO, V.H. Efeito da adubação mineral e orgânica sobre a produtividade e tamanho de frutos de tomate. Horticultura Brasileira, Brasília, v 8, n. 1, p. 17-18, 1990.

STRECK, N.A.; BURIOL, G.A.; SCHNEIDER, F.M. Efeito da densidade de plantas sobre a produtividade do tomateiro cultivado em estufa de plástico. Pesquisa Agropecuária Brasileira, Brasília, v. 31, n. 2, p. 105-112, 1996.

TANAKA, A; FUJITA, K.; KIKUCHI, K. NutrioPhysiological studies on the tomato plant. I. Outline of growth and nutrient absorption. Soil Science Plant Nutrition, Tokio, v. 20, n. 1, p. 57-68, 1974

RIZZO, A.A.N.; BRAZ, L.T. Características de cultivares de melão rendilhado cultivadas em casa de vegetação. Horticultura Brasileira, Brasília, v. 19, n. 3, p. 237-240, novembro 2.001 . 